\title{
ОСОБЛИВОСТІ МРТ-ВІЗУАЛІЗАЦІЇ МІОМ МАТКИ НА ПЕРЕДОПЕРАЦІЙНОМУ ЕТАПІ
}

\section{Особливості МРТ-візуалізації міом матки на передопераційному етапі}

\section{д. М. Железов}

Одеський національний медичний університет КНП «Пологовий будинок № 5», м. Одеса

Вступ. Міома матки є доброякісною моноклональною пухлиною гладенької мускулатури матки, яка, як правило, має множинний мультимодальний характер, але може й виникати у вигляді поодиноких міоматозних вузлів. Лейоміома матки є одним із найчастіших гінекологічних захворювань у жінок і складає в репродуктивному віці, за даними різних авторів, від 10 до $40 \%$.

Мета дослідження - оцінити діагностичну цінність MPT-візуалізації міом матки на передопераційному етапі.

Матеріали і методи. Дослідження виконано на базі Обласного перинатального чентру та КНП «Пологовий будинок № 5» (м. Одеса). Обстежено 35 жінок із виявленою під час УЗД міомою матки. Усім пацієнткам проводили MPT-дослідження за допомогою апарату «Siemens Symphony» (Німеччина). В подальшому пацієнткам проводилися оперативні втручання: у 20 випадках консервативну міомектомію, у 15 - гістеректомію. Статистичну обробку проводили за методами дисперсійного аналізу із застосуванням програмного забезпечення Statistica 13.5 (StatSoft Inc., США).

Результати. При зіставленні результатів МРTдослідження з даними попереднього УзД-скринінгу та гістологічного аналізу видалених під час оперативного втручання міоматозних вузлів встановлено, що специфрічність методу МРТ складає 100 \%, чутливість - 97,1 \%, що відповідає коефріцієнта Юдена J=0,97.

Висновки. МРТ-дослідження має високу діагностичну цінність та може бути рекомендоване для уточнення діагнозу в складних клінічних випадках. Найчастіше зустрічаються гіперденсивні міоматозні вузли з низькою інтенсивністю накопичення контрасту.

Ключові слова: міома матки; діагностика; магнітно-резонансна томографрія.

\section{ВСТУП}

Міома матки є доброякісною моноклональною пухлиною гладенької мускулатури матки, яка, як правило, має множинний мультинодальний харак-
Features of MRI imaging of uterine fibroids in the preoperative stage

\section{M. Zhelezov}

Odesa National Medical University

Maternity Hospital No. 5, Odesa

e-mal: zhelezoff@i.ua

Summary. Uterine fibroids are benign monoclonal tumors of uterine smooth muscle, which usually have multiple multimodal nature, but can also occur in the form of single fibroids. Uterine leiomyoma is one of the most common gynecological diseases in women and is of reproductive age, according to various authors, from 10 to $40 \%$.

The aim of the study - to assess the diagnostic value of MRI imaging of uterine fibroids in the preoperative stage.

Materials and Methods. The study was performed on the basis of the Regional Perinatal Center and the Maternity Hospital No. 5 (Odesa). 35 women with uterine fibroids detected by ultrasound were examined. All patients underwent MRI examination using Siemens Symphony (Germany). Subsequently, patients underwent surgery: in 20 cases conservative myomectomy in 15 - hysterectomy. Statistical processing was performed by analysis of variance using Statistica 13.5 software (StatSoft Inc., USA).

Results. Comparing the results of MRI examination with the data of previous ultrasound screening and histological analysis of myomas removed during surgery, it was found that the specificity of the MRI method is $100 \%$, sensitivity $-97.1 \%$, which corresponds to the Juden coefficient $\mathrm{J}=0.97$.

Conclusions. MRI examination has a high diagnostic value and can be recommended to clarify the diagnosis in complex clinical cases. The most common hyperdensive myomas with low intensity of contrast accumulation.

Key words: uterine fibroids; diagnosis; magnetic resonance imaging.

тер, але може й виникати у вигляді поодиноких міоматозних вузлів. Лейоміома матки (ЛМ) є одним 3 найчастіших гінекологічних захворювань у жінок і складає в репродуктивному віці, за даними різних 
авторів, від 10 до 40 \% [1-3]. Залежно від методу реєстрації зустрічальність ЛМ коливається від 1-5 \% (диспансерні огляди практично здорових жінок) до 30-75 \% (синтропія у гінекологічних хворих) [4]. У багатьох жінок на момент виявлення ЛМ репродуктивна фрункція не реалізована - за даними літератури найчастіше захворювання діагностують у жінок у віці 35 років та старше. 3 іншого боку, зростає частота виявлення ЛМ у молодих жінок й навіть дівчат. Ці випадки можуть мати спадковий характер і частково пояснюються поширенням більш досконалих методів візуалізації.

Одним із них $є$ магнітно-резонансна томограсрія (МРТ). Цей метод був упроваджений наприкінці 70-х років минулого сторіччя. Ще у 1973 р. профресор хімії Пол Лотербур опублікував у журналі «Nature» статтю «Формування зображень за допомогою індукованої локальної взаємодії: приклади застосування ядерного магнітного резонансу» [5], а вже за декілька років після цієї публікації професор фрізики Ноттінгемського університету Пітер Менссрілд розробив математичний метод, завдяки якому сканування займало декілька секунд, а не годин, і який дозволив отримувати більш чітке зображення [6]. 3 того часу почався тріумфальний поступ методу, який швидко набув популярності в усіх галузях медицини. На жаль, він має й обмеження. Це наявність імплантованих феромагнітних металевих конструкцій або сторонніх тіл, татуювання 3 металовмісними пігментами, інсулінові помпи; стимулятори ЦНС та вагуса; неферомагнітні імплантати внутрішнього вуха; кровоспинні кліпси (крім судин мозку); декомпенсована серцева недостатність; перший триместр вагітності; неадекватність пацієнта; ШВР, клаустрофобія, епілепсія, тяжкий загальний стан пацієнта [7-9]. Крім того, порівняно з іншими методами візуалізації, він $€$ відносно дорогим [7].

Незважаючи на те, що ультрасонографрічне дослідження залишається основним методом візуалізаційної діагностики у пацієнток sз ЛМ [1, 2], MPT має значно вищу резолютивну здатність, а у випадках складних клінічних ситуацій із наявністю супутніх захворювань органів малого таза $€$ оптимальним методом, особливо при визначенні обсягу планованого оперативного втручання [6, 8].

Метою дослідження було оцінити діагностичну цінність МРТ-візуалізації міом матки на передопераційному етапі.

\section{МАТЕРІАЛИ I МЕТОДИ}

Дослідження виконано на базі Обласного перинатального центру та КНП «Пологовий будинок № 5» (м. Одеса). Обстежено 35 жінок із виявленою під час УЗД міомою матки. Усім пацієнткам проводили МРТ-дослідження за допомогою апарату
«Siemens Symphony» (Німеччина). В подальшому пацієнткам проводили оперативні втручання: у 20 випадках консервативну міомектомію, у 15 - гістеректомію.

Стандартний протокол візуалізації міоми матки включає наступні послідовності: осьову, сагітальну та корональну швидку спін-ехозважену послідовність T2, осьову динамічну 3D-насичену жиром зіпсовану послідовність градієнт-ехо (отримання таза із пришвидшенням об'єму) до та після введення контрасту агента, і відстрочена 2D-осьова, сагітальна та корональна послідовність градієнтехо. Гадоліній - місткий контраст (гадовіст) 0,05 ммоль/кг вводили внутрішньовенно зі швидкістю 2-3 мл/с автоматичним ін'єктором, після чого проводили промивання сольовим розчином в об'ємі 30 мл. Для визначення затримки сканування після введення контрасту вводили 2 мл болюсу для оптимізації отримання артеріальної фрази. Всі послідовності виконували із затримкою дихання у кінці дихання.

Усі зображення розглянув досвідчений радіолог, а зовнішній вигляд міоми класифікований за інтенсивністю сигналу в одну з чотирьох груп у зважених МРТ-серіях Т1 та Т2. Міома на зважених зображеннях Т1 була ідентифікована як ізоінтенсивна, гіпоінтенсивна, гіперінтенсивна або гетерогенна порівняно 3 міометрієм. Міому класифрікували як гетерогенну, якщо вона виглядала як гіпо-, так і гіперінтенсивна порівняно 3 міометрієм. На Т2зважених зображеннях міому знову класифікували на чотири групи за інтенсивністю сигналу, порівняно 3 міометрієм; міома виявилася ізоінтенсивною, яскравою або темною. Потім темні міоми Т2 класифрікували далі як такі, що мають мінімальну неоднорідність або значну неоднорідність, якщо міома мала зони високої та низької інтенсивності сигналу. Посилення контрасту гадолінію оцінювали за інтенсивністю сигналу міоми порівняно 3 міометрієм. У багатьох жінок спостерігалася множинна міома, і тому найбільшу за розмірами міому відбирали для об' ємного та візуального характеристичного аналізу.

Статистичну обробку проводили за методами дисперсійного аналізу із застосуванням програмного забезпечення Statistica 13.5 (StatSoft Inc., США).

\section{РЕЗУЛЬТАТИ Й ОБГОВОРЕННЯ}

Середній вік обстежених жінок склав $(43,2 \pm 1,8)$ року. Переважали випадки 3 множинним міоматозом, у значної кількості жінок виявляли супутні гінекологічні та соматичні захворювання. Найчастіше були поєднання міоми 3 гіперпластичними процесами ендометрія та аденоміозом, рідше - 3 доброякісних пухлинами яєчників. Генітальний пролапс I-II ступенів відзначали 7 (20,0%) жінок. 
Переважали метрорагія (85,7 \%), дисменорея (40,0 \%), дизуричні явища (37,1 \%) та больовий синдром (80,0 \%). При подальшому аналізі встановлено, що візуалізація міоми на МРТ дозволяє достатньо чітко диференціювати міоматозні вузли за щільністю та вираженням дегенеративних процесів.

Вигляд міоми класифрікували за інтенсивністю сигналу на одну з чотирьох груп у зважених серіях MPT Т1 та Т2. Міоми на зображеннях, зважених за допомогою Т1, були ідентифріковані, як ізоінтенсивні $(80,0 \%)$, гіпоінтенсивні $(8,6 \%)$, гіперінтенсивні $(2,9 \%)$ або гетерогенні $(8,6 \%)$ порівняно 3 міометрієм. На Т2-зважених зображеннях міому іденти-
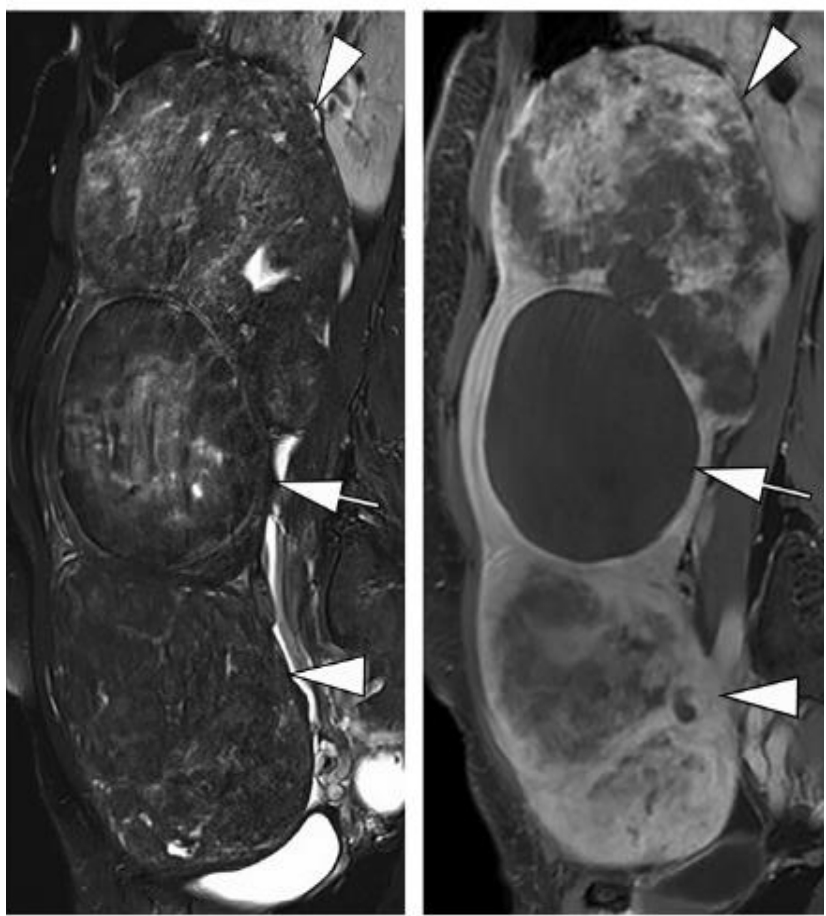

Рис. 1. Випадок міоми матки у 40-річної жінки. Візуалізується великий інтрамуральний (тип 4 за FIGO) та субсерозний (тип 5 за FIGO) Після введення контрасту (праворуч) спостерігається гетерогенне посилення субсерозного вузла (позначено стрілками).

\section{ВИСНОВКИ}

1. МРТ-дослідження має високу діагностичну цінність та може бути рекомендоване для поточнення діагнозу в складних клінічних випадках.

\section{СПИСОК ЛІТЕРАТУРИ}

1. De La Cruz M. S. Uterine fibroids: diagnosis and treatment / M. S. De La Cruz, E. M. Buchanan // Am. Fam. Physician. - 2017. - Vol. 95 (2). - P. 100-107. - Access mode : https://www.aafp.org/afp/2017/0115/p100.html.

2. Uterine fibroids / E. A. Stewart, S. K. LaughlinTommaso, W. H. Catherino [et al.] // Nat. Rev. Dis. Primers. - 2016. - Vol. 2. - 16043. - Access mode : https://doi. org/10.1038/nrdp.2016.43. фрікували як темну 3 мінімальною неоднорідністю (68,6 \%), темну зі значною неоднорідністю (20,0 $\%)$, ізоінтенсивну (5,7 \%) або яскраву $(5,7$ \%) інтенсивність сигналу.

Наводимо приклади визначення ЛМ за допомогою МРТ (рис. 1, 2).

При зіставленні результатів МРТ-дослідження 3 даними попереднього УЗД-скринінгу та гістологічного аналізу видалених під час оперативного втручання міоматозних вузлів встановлено, що специфічність методу МРТ складає 100 \%, чутливість - 97,1 \%, що відповідає коефіцієнту Юдена $\mathrm{J}=0,97$.

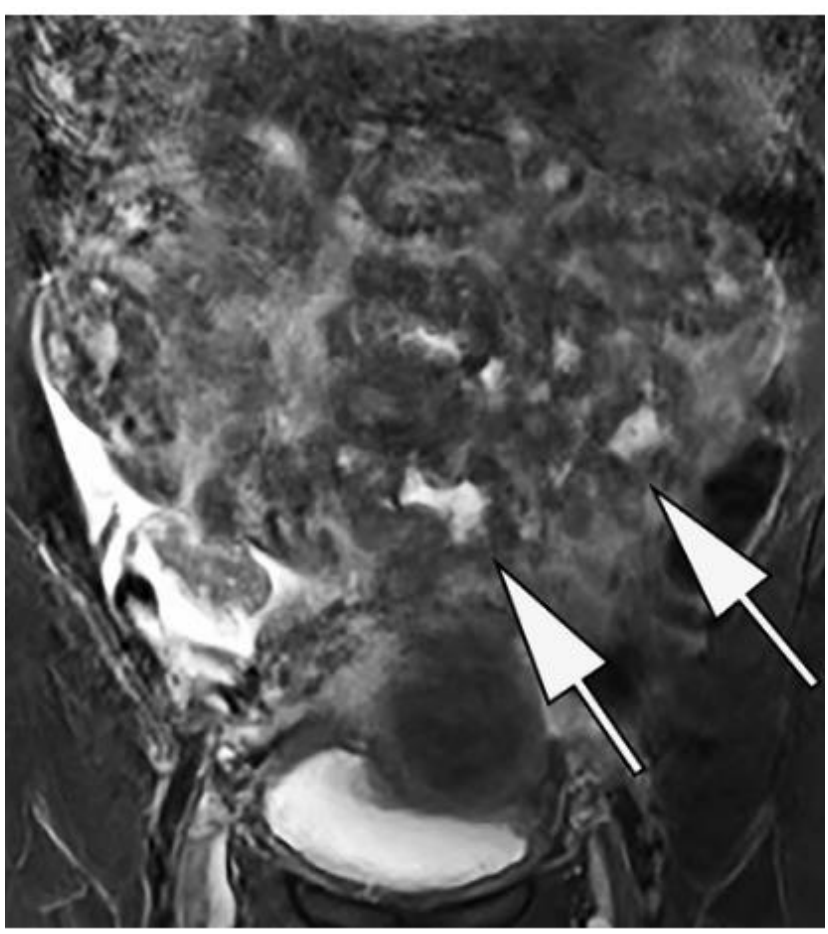

Рис. 2. МРТ Т2-зображення збільшеної матки із множинними гіпоінтенсивними вузлами з ознаками некрозу.

2. Найчастіше зустрічаються гіперденсивні міоматозні вузли з низькою інтенсивністю накопичення контрасту. 
5. Lauterbur P. Image formation by induced local interactions: Examples employing nuclear magnetic resonance / P. Lauterbur // Nature. - 1973. - Vol. 242. P. 190-191. -Access mode: https://doi.org/10.1038/242190a0.

6. Raymond V. Damadian, M.D.: magnetic resonance imaging and the controversy of the 2003 Nobel Prize in Physiology or Medicine / R. J. Macchia, J. E. Termine, C. D. Buchen [et al.] // J. Urol. - 2007. - Vol. 178 (3 Pt 1). P. 783-785. - Access mode : https://doi.org/10.1016/j. juro.2007.05.019.

7. MR-guided focused ultrasound for uterine fibroids: a preliminary study of relationship between the treatment outcomes and factors of MR images including elastography /

\section{REFERENCES}

1. De La Cruz MS, Buchanan EM. Uterine fibroids: diagnosis and treatment. Am Fam Physician. 2017;95(2): 100-7. Available from: https://www.aafp.org/afp/2017/0115/ p100.html.

2. Stewart EA, Laughlin-Tommaso SK, Catherino WH, Lalitkumar S, Gupta D, Vollenhoven B. Uterine fibroids. Nat Rev Dis Primers. 2016;2:16043. Available from: https://doi. org/10.1038/nrdp.2016.43.

3. Al-Hendy A, Myers ER, Stewart E. Uterine fibroids: burden and unmet medical need. Semin Reprod Med. 2017;35(6): 473-80. Available from: https://doi. org/10.1055/s-0037-1607264.

4. Yu O, Reed SD, Schulze-Rath R, Grafton J, Hansen K, Scholes D. Identification of incident uterine fibroids using electronic medical record data. EGEMS (Wash DC). 2019;7(1): 5. Available from: https://doi.org/10.5334/ egems.264.

5. Lauterbur P. Image formation by induced local interactions: examples employing nuclear magnetic resonance. Nature. 1973;242:190-1. Available from: https:// doi.org/10.1038/242190a0.
S. Ichikawa, U. Motosugi, M. Omori [et al.] // Magn. Reson. Med. Sci. - 2019. - Vol. 18 (1). - P. 82-87. - Access mode : https://doi.org/10.2463/mrms.tn.2017-0103.

8. Prognostic value of pre-embolisation MRI features of uterine fibroids in uterine artery embolisation / I. Kalina, A. Tóth, É. Valcseva [et al.] // Clin. Radiol. - 2018. Vol. 73 (12). - P. 1060.e1-1060.e7. - Access mode : https:// doi.org/10.1016/j.crad.2018.08.009.

9. A practical guide to MR imaging safety: what radiologists need to know / L. L. Tsai, A. K. Grant, K. J. Mortele [et al.] // Radiographics. - 2015. - Vol. 35 (6). - P. 1722-1737. - Access mode: https://doi.org/10.1148/ rg. 2015150108 .

6. Macchia RJ, Termine JE, Buchen CD. Raymond V. Damadian, M.D.: magnetic resonance imaging and the controversy of the 2003 Nobel Prize in Physiology or Medicine. J Urol. 2007;178(3 Pt 1): 783-5. Available from: https://doi.org/10.1016/j.juro.2007.05.019.

7. Ichikawa S, Motosugi U, Omori M, Sano K, Omiya Y, Hirata S, Onishi H. MR-guided focused ultrasound for uterine fibroids: a preliminary study of relationship between the treatment outcomes and factors of $\mathrm{mr}$ images including elastography. Magn Reson Med Sci. 2019;18(1): 82-7. Available from: https://doi.org/10.2463/mrms.tn.2017-0103.

8. Kalina I, Tóth A, Valcseva É, Kaposi PN, Ács N, Várbíró S, Bérczi V. Prognostic value of pre-embolisation MRI features of uterine fibroids in uterine artery embolisation. Clin Radiol. 2018;73(12): 1060.e1-e7. Available from: https://doi.org/10.1016/j.crad.2018.08.009.

9. Tsai LL, Grant AK, Mortele KJ, Kung JW, Smith MP. A practical guide to MR imaging safety: what radiologists need to know. Radiographics. 2015;35(6): 1722-37. Available from: https://doi.org/10.1148/rg.2015150108. 